AperTO - Archivio Istituzionale Open Access dell'Università di Torino

\title{
Artificial lighting triggers the presence of urban spiders and their webs on historical buildings
}

\section{This is the author's manuscript}

Original Citation:

\section{Availability:}

This version is available http://hdl.handle.net/2318/1676420

since 2019-03-08T11:48:06Z

Published version:

DOI:10.1016/j.landurbplan.2018.09.003

Terms of use:

Open Access

Anyone can freely access the full text of works made available as "Open Access". Works made available under a Creative Commons license can be used according to the terms and conditions of said license. Use of all other works requires consent of the right holder (author or publisher) if not exempted from copyright protection by the applicable law. 
and Urban Planning

Elsevier Editorial System(tm) for Landscape

Manuscript Draft

Manuscript Number: LAND-D-18-00321R1

Title: Artificial lighting triggers the presence of urban spiders and their webs on historical buildings

Article Type: Research paper

Keywords: urban ecology; digital image analysis; light pollution;

Araneae; synanthropic species; aesthetic nuisance

Corresponding Author: Dr. Marco Isaia, Ph.D.

Corresponding Author's Institution: University of Torino

First Author: Stefano Mammola, Ph.D.

Order of Authors: Stefano Mammola, Ph.D.; Marco Isaia, Ph.D.; Daniele Demonte; Paolo Triolo; Marco Nervo

Abstract: Different spider species living in the urban environment spin their webs on building facades. Due to air pollution, web aggregations entrap dirt particles over time, assuming a brownish-greyish colouration and thus determining an aesthetic impact on buildings and street

furniture. In Europe, the most common species causing such an aesthetic nuisance is Brigittea civica (Lucas) (Dictynidae). In spite of the socioeconomical relevance of the problem, the ecological factors driving the proliferation of this species in the urban environment are poorly described and the effectiveness of potential cleaning activities has never been discussed in scientific literature. Over one year, we studied the environmental drivers of $\mathrm{B}$. civica webs in the arcades of the historical down-town district of Turin (NW-Italy). We selected a number of sampling plots on arcade ceilings and we estimated the density of $B$. civica webs by means of digital image analysis. In parallel, we collected information on a number of potential explanatory variables driving the arcade colonization, namely artificial lighting at night, substrate temperature, distance from the main artificial light sources and distance from the river. Regression analysis showed that the coverage of spider webs increased significantly at plots with higher light intensity, with a major effect related to the presence of historical lampposts with incandescent lamps rather than halogen lamps. We also detected a seasonal variation in the web coverage, with significant higher values in summer. Stemming from our results, we are able to suggest good practices for the containment of this phenomenon. 


\section{Dr. Marco Isaia}

Department of Life Science and Systems Biology

University of Turin

Via Accademia Albertina, 13 - 10123 Torino

Tel. 0116704519

E-mail:marco.isaia@unito.it

May $07^{\text {th }}, 2018$

Dear Dr Xiang,

we hereby submit the revised version of manuscript LAND-D-18-00321 entitled "Artificial lighting triggers the presence of urban spiders and their webs, causing an aesthetic damage to historical buildings" intended for publication in Landascape and Urban Planning.

We thank you for handling our submission and spending time in evaluating it. In this revision, we have took into account all minor corrections suggested by referee 2 and proof-read it once more.

We confirm that the work is all original research carried out by the authors, all authors agree with the contents of the manuscript and its submission to the journal, no part of the research has been published in any form elsewhere, and the manuscript is not being considered for publication elsewhere.

Yours,

Dr Marco Isaia

On behalf of all co-authors

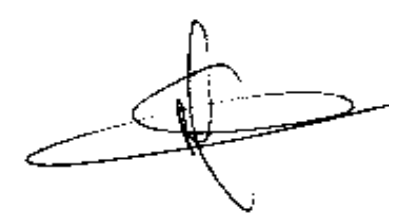




\section{${ }^{*}$ Detailed Response to Reviewers}

\section{REBUTTAL LETTER FOR}

LAND-D-18-00321

\section{'Artificial lighting triggers the presence of urban spiders and their webs on historical buildings'}

\section{Reviewer \#2: Landscape and Urban Planning MS 18-0321}

This seems to be a respectable contribution suitable for publication. It is a nice combination of science addressing a real world problem. It also is a relatively clean paper. I usually find lots of mistakes in manuscripts that I review but this one had few errors. One caveat is that I have very limited statistical background so the editor needs to make sure that someone with statistical ability reviews the paper.

RESPONSE: Thank you for spending time to review our manuscript and for you very positive attitude toward it.

There are several instances of misspelling the spider family name as "Dyctinidae" which needs correcting (lines 45, 505, 506)

\section{RESPONSE: Corrected.}

line 47: cited as Hertel 1969 in the text but 1968 in the reference section

RESPONSE: Corrected - the right one was 1968.

line 217: citation is "XXXXXXX" but is probably Hanggi which is not cited in the paper and is also 2016

RESPONSE: Actually, this is not a mistake. From the journal's guidelines (see highlight in colour):

"Landscape and Urban Planning uses a double-blind review process, and to ensure anonymity the manuscript file must not include any self-referencing, logos, headers or any other type of information or formatting that might reveal the identify or affiliation of any of the authors. Acknowledgements should not be included in the manuscript file and must be uploaded as a separate file. See Section 3.9.7 below. Self-references that must be included must not be obvious in revealing any authors' identify and should refer to the authors' work only indirectly (e.g., "This work builds upon procedures developed by Smith (2010)"; NOT "I build upon my previous work (Smith, 2010)..."). To further ensure anonymity, authors may choose to temporarily remove self-citations from the reference list and mask in-text references (e.g., "(XXX, 2009 masked for blind review)"), then restore the proper citation when the manuscript is accepted. Although such an approach better respects the integrity of the blind review process, authors must weigh the removal of a citation against the need for reviewers to evaluate the credibility of your work."

On the other hand, we now reference the missing reference in the text (Hanggi).

line 62: change "environment" to "environments"

line 152: insert a space in "Photo\#2"

line 175: change "generated" to "generate"

line 270: change "them" to "themselves"

line 287: I would change "Southern" to "southern"

line 350: change "spider" to "spiders"

line 352: I would change "Southern" to "southern"

line 484: insert a space in "seriesmodel" 
56 line 541: many other citations have a long list of authors, whereas this one just has the first author and et al.

57 line 590s: Vetter paper should be listed before Vitousek

58 line 620: add a space in "typeanalyses"

69 RESPONSE: Done. 
1 Artificial lighting triggers the presence of urban spiders and their webs on historical

2 buildings

3

4 Stefano MAMMOLA ${ }^{1,2}$

5 stefanomammola@gmail.com

6

7 Marco ISAIA ${ }^{2, *}$

8 marco.isaia@unito.it

9 tel: 0116704544

10 fax: 0116704508

12 Daniele DEMONTE ${ }^{1}$

13 daniele.demonte@centrorestaurovenaria.it

15 Paolo TRIOLO ${ }^{1}$

16 paolo.triolo@centrorestaurovenaria.it

18 Marco NERVO $^{1}$

19 marco.nervo@centrorestaurovenaria.it

23 1. Fondazione Centro per la Conservazione ed il Restauro dei Beni Culturali "La Venaria 24 Reale". Venaria Reale, Italy

26 2. Department of Life Sciences and Systems Biology, University of Turin. Torino, Italy 27

28 * corresponding author 
1. Spider web aggregations affect the aesthetic value of historical building

2. We studied the ecological factors driving the abundance of spider webs on historical arcade ceilings

3. Web density was estimated using an innovative photographic-based methodology

4. By attracting prey, incandescent artificial lighting is the major factor driving of the increase of spider webs

5. Changing the lighting system type may help in reducing this problem 
1 Artificial lighting triggers the presence of urban spiders and their webs on historical

2 buildings

3

4

5 Abstract

6

7 Different spider species living in the urban environment spin their webs on building

8 facades. Due to air pollution, web aggregations entrap dirt particles over time, assuming a

9 brownish-greyish colouration and thus determining an aesthetic impact on buildings and

10 street furniture. In Europe, the most common species causing such an aesthetic nuisance

11 is Brigittea civica (Lucas) (Dictynidae). In spite of the socio-economical relevance of the

12 problem, the ecological factors driving the proliferation of this species in the urban

13 environment are poorly described and the effectiveness of potential cleaning activities has

14 never been discussed in scientific literature. Over one year, we studied the environmental

15 drivers of $B$. civica webs in the arcades of the historical down-town district of Turin (NW-

16 Italy). We selected a number of sampling plots on arcade ceilings and we estimated the

17 density of $B$. civica webs by means of digital image analysis. In parallel, we collected

18 information on a number of potential explanatory variables driving the arcade colonization,

19 namely artificial lighting at night, substrate temperature, distance from the main artificial

20 light sources and distance from the river. Regression analysis showed that the coverage of

21 spider webs increased significantly at plots with higher light intensity, with a major effect

22 related to the presence of historical lampposts with incandescent lamps rather than

23 halogen lamps. We also detected a seasonal variation in the web coverage, with

24 significant higher values in summer. Stemming from our results, we are able to suggest

25 good practices for the containment of this phenomenon.

27 Keywords: urban ecology; digital image analysis; light pollution; Araneae; synanthropic 28 species, aesthetic nuisance 


\section{INTRODUCTION}

31 Environmental modifications driven by urbanization have a significant effect on biodiversity

32 (Güneralp \& Seto, 2013; Seto, Gueneralp, \& Hutyra, 2012; Vitousek, 1997), driving large

33 changes in species abundances and distributions within the original biological communities

34 (McKinney, 2008). Whilst urbanization is considered to be a major determinant of

35 biodiversity loss (Grimm et al., 2008; Newbold et al., 2015), a number of organisms are

36 able to coexist alongside us in urban environments (e.g., Aronson et al., 2014; Bertone et

37 al., 2016; McKinney, 2002). Owing to their high ecological plasticity (Turnbull, 1973),

38 several species of spiders are able to dwell in cities, representing an important component

39 of the urban wildlife (McIntyre, 2000; Shochat, Stefanov, Whitehouse, \& Faeth, 2004;

40 Taucare-Ríos, Brescovit, \& Canals, 2013). With the exception of some species of medical

41 importance (e.g. Isbister et al., 2005; Sams et al., 2001; Vetter \& Isbister, 2008), urban

42 spiders usually have little socio-economic impacts and often remain unnoticed. A

43 remarkable exception is found in those spider that due to their webs may cause aesthetic

44 alterations to buildings facades - see discussion in Nentwig (2015).

In Europe, one of the most noticeable species causing aesthetic nuisance to

46 buildings is Brigittea civica (Lucas) (Araneae: Dictynidae) (Figure 1A) (Samu, Jozsa, \&

47 Csànyi, 2004). This is a small cribellate spider (body length 2.3-3.5 mm; Nentwig, Blick,

48 Gloor, Hänggi, \& Kropf, 2018) of South European origin (Hertel, 1968), which spins a

49 circular, tangled cribellate cobweb on flat surfaces (Billaudelle, 1957; Krumpálová, 2001).

50 Although being relatively small in size (ca. $5 \mathrm{~cm}$ in diameter), cobwebs of $B$. civica may

51 occur at very high density on wall facades and can persist for long periods of time (Figure

52 1B-D). The fact that multiple individuals are able to coexist and spin their cobwebs at a

53 very close distance to one another can be explained in light of the peculiar behaviour of $B$.

54 civica, with different individuals being able to share prey without fighting each other

55 (Billaudelle, 1957). Due to air pollution, these large web aggregations entrap dust and dirt 
particles over time, assuming a brownish-greyish coloration and thus significantly reducing

57 the aesthetic value of buildings (Havlová \& Hula, 2010; Kostanjšek \& Celestina, 2008;

58 Nedvěd et al., 2011; Novotný, Hula, \& Niedobová, 2017; Samu et al., 2004; Figure 1D, E).

59 The factors determining this phenomenon are as yet poorly described, and thus no

60 good practices have been put forward to address this problem and to maximize the

61 effectiveness of potential cleaning activities. To the best of our knowledge, the only study

62 referring to habitat selection by B. civica was conducted by Samu et al. (2004) in urban

63 environments in Hungary. The authors demonstrated quantitatively how web density is

64 significantly higher in facades with a southern exposure and sheltered to external

65 weathering (especially rain), whereas they found no clear pattern in the selection of

66 different surface-types.

67 Because of its artistic heritage from one side and of its predominantly

68 Mediterranean climate suitable for B. civica on the other, Italy is potentially among the

69 most affected countries by this issue. In several Italian heritage cities, webs of this spider

70 are found on churches, arcades, palaces and other historical buildings exploited for

71 touristic purposes, resulting in possible economic impacts connected to the cleaning

72 activities aimed at removing the webs.

73 We conducted a one-year field study to identify the environmental factors driving the

74 proliferation of $B$. civica webs in the arcades of the historical down-town district of Turin

75 (NW-Italy) (Figure 1E). Observations made by the authors during a preliminary site

76 inspection, and similar recorded observations published by Samu et al. (2004), lead to an

77 initial prediction that i) the density of webs is significantly higher in the vicinity of artificial

78 lighting systems and in other areas with high illuminance. Moreover, given that webs of $B$.

79 civica may last for long time on the surfaces, we further hypothesize that ii) webs are

80 present through the year, but there should be variation in their density connected with the

81 phenology of the species. In particular, increases in the density of webs may be expected 
82 right after the breeding period for this species, approximately from April to June 83 (Kostanjšek \& Celestina, 2008; Nentwig et al., 2018; Wiehle, 1953). 


\subsection{Study area}

87 This study was conducted in the municipality of Turin (Torino), NW-Italy $\left(45^{\circ} 04^{\prime} \mathrm{N}, 7^{\circ} 42^{\prime}\right.$

88 E). The city has a long history, testified by the traditional orthogonal plant of the ancient 89 Roman camps ("castrum"), and the remarkable Baroque architecture, which was 90 developed under the Duchy of Savoy (1416-1860). The down-town district of Turin has 18

91 kilometres of historical Baroque arcades ("portici"), mostly interconnected with each other,

92 making it one of the largest pedestrian areas in Europe. Arched ceilings represent suitable

93 habitats to Brigittea civica spiders, being naturally sheltered from rains, direct solar 94 irradiation, and air currents (Billaudelle, 1957; Samu et al., 2004). As a result, most 95 arcades ceilings are heavily colonized by $B$. civica cobwebs (Figure 1B-D). In order to 96 improve the aesthetic value of the historical district, the competent authorities promoted 97 the cleaning of the arcades in 2006, when the city hosted the XX Olympic Winter Games. We conducted our study in the heart of the historical down-town district, on the 99 arcades connecting Piazza Vittorio Veneto to Piazza Castello all along Via Po, for 100 approximately 2 kilometres. In this area, arcades are predominantly Serlian-type arches, 101 ranging from 3 to $5 \mathrm{~m}$ in height (Figure $1 \mathrm{E}$ ). The majority of the arcades have vaulted 102 ceilings, with some exceptions (coffered ceilings) along a small stretch of Via Po, which we 103 did not consider in this analysis. At night, arcades are illuminated by historical lampposts 104 with incandescent lights and/or halogen lamps, which are installed at different heights.

\subsection{Data collection}

107 We conducted three monitoring sessions over one year (Winter: 10 Dec 2016; Spring: 30 108 Apr 2017; Summer: 7 Jul 2017), at night. In order to provide a homogeneous coverage of 109 the entire study area, we selected seventy-two arcades as basic sample units, 
110 approximately equidistant. All sampling plots were georeferenced. Within each basic

111 sample unit, at each survey we randomly identified one sampling plot of $1.0 \times 0.7 \mathrm{~m}$ on a

112 flat area of the ceiling (i.e. avoiding angles and cracks and crevices in the plaster). Using

113 this study design, we were able to control for substrate type (all arcade ceilings are

114 characterized by the same plaster type) and general exposure to external weather (all

115 arcades are protected by rains, direct solar irradiation, and air currents).

116 We conducted the monitoring by means of a photography-based methodology

117 (Figure 2), by taking two photos of each sampling plot in order to estimate the density of 118 Brigittea civica webs (photo \#1) and the intensity of artificial lighting illuminating the wall

119 surface of the plot (photo \#2). Full details on the calculation of these variables are given in

120 the section "Photographic analysis". At each survey, we further measured the substrate

121 temperature with an infrared thermometer at the centre of the sampling plot, and we

122 calculated the linear distance from 1) the closest historical lamppost (incandescent lighting

123 system) and/or 2) the closest halogen light (Figure 2). The distance of each sampling plot

124 from the Po River, which is flowing close to the study area (see Figure 3), was further

125 calculated in a GIS environment (ArcView 3.3 ESRI). This latter variable was introduced to

126 account for the potential influence of local microclimatic factors related to the proximity of

127 water on web abundance and insect prey availability - e.g. as observed in other web

128 weaver spiders (Akamatsu, Toda, \& Okino 2004, Gillespie, 1987; Kleinteich, 2010). 


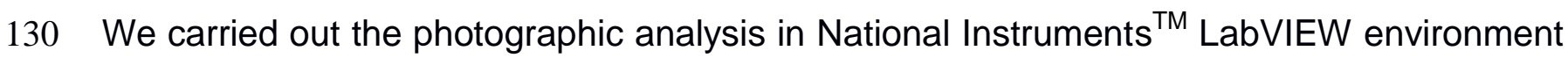

131 (Elliott, Vijayakumar, Zink, \& Hansen, 2007). In order to obtain a value representing the

132 web coverage of each plot, we acquired a photo of the plot (photo \#1) in raw mode with a

133 Nikon D810 camera equipped with a Nikon sb910 flash; the image was then converted to

13416 bit greyscale. Initially we conducted a set of exploratory tests, applying different pixel

135 thresholds for converting the 16 bit greyscale image into a black and white (B/W) image.

136 The aim of the B/W conversion was to recolour the pixels depicting webs of Brigittea civica

137 in black and the remaining pixels in white, thus allowing an estimation of the web coverage

138 within the plot. After the preliminary trial, we set the B/W conversion threshold at 49000

139 (where 0 is black and 65535 is white), which proved to be the best trade-off value to

140 separate the webs from other features of the surface within the image - i.e. dust particles

141 on the substrate or darker areas due to the natural ruggedness of the ceiling plaster. We

142 used this fixed threshold for converting all images into B/W, and we summed up the

143 number of black pixels via an automated function.

144 Despite the evaluation of the light intensity that reaches a surface is normally 145 performed directly using a photoradiometer, in our case this resulted highly impractical due 146 to the height of the arcades and the number of plots. Starting from the assumption that the 147 intensity of the light reflected by a surface is correlated with the intensity of the lighting 148 source, we used an evaluation method based on the acquisition of the reflected light with a 149 camera. By choosing surfaces having more or less the same colour and the same surface 150 morphology, and by setting up a fixed exposure time and no flash, it is possible to use the 151 acquired image as an indirect measure of the light intensity of the plot. Consequently, 152 images with low values of $R, G$ and $B$ channels correspond to low values of light intensity 153 reaching the surface, while high values of $R, G$ and $B$ channels correspond to high values 154 of light intensity. For this calculation, we acquired a second image of the plot (photo \#2) 
155 focusing on a web-free surface (Figure 2). Photo \#2 was taken in raw mode with a Nikon

156 D3X camera without flash and using a fixed exposure. We converted the digital image to a

15716 bit RGB, and we derived the histogram representing the distribution of the overall pixel

158 values (range 0 - 65535). We used the modal value - i.e., the most recurrent value in the

159 image - as an indirect measure of the artificial light intensity that illuminated the

160 photographed surface. We repeated the same operation for each of the RGB channels in

161 order to explore possible relationships between the web coverage and different colours of 162 light.

163

$164 \quad 2.4$ Regression analysis

165 We studied the relation between environmental factors and Brigittea civica web coverage 166 by performing a regression-type analysis (Zuur \& leno, 2016) in R (R core team, 2017).

167 We expressed the dependent variable as the counts of black pixels (i.e. pixel covered with 168 webs) within photo \#1 - hereinafter "web coverage" (WEB). We selected the following 169 covariates (explanatory variables) as potential drivers of the web coverage in the sampled 170 plots: distance from the river (Dst; continuous variable), substrate temperature $\left(\mathrm{T}^{\circ}\right.$; 171 continuous variable), sampling session (Sampling; categorical variable of three levels), 172 artificial light intensity (ILL; continuous variable calculated from photo \#2), Red, Green and

173 Blue light components ( $R, G, B$, respectively; continuous variables calculated from photo 174 \#2), distance from the nearest historical lamppost (Dst_lamp; continuous variable) and 175 distance from halogen light sources (Dst_halo; continuous variable). In order to account for 176 potential density-dependent effects in driving the web coverage (i.e. spatial relationships 177 among webs), we further included a variable reflecting the intercrossed distance of each 178 plot from the others (InterDst; continuous variables). To generate this variable, we 179 calculated the distance matrix of each sampling plot using the spatial coordinates of the 180 plots, and derived the mean distance of each plot from the others. We tested for spatial 
181 autocorrelation in web coverage via Moran's I test in the ape R package (Paradis, Claude,

182 \& Strimmer, 2004), using the Gittleman and Kot (1990) method.

183 We initially explored the dataset using the standard protocol described by Zuur, 184 leno, and Elphick (2010). We constructed Cleveland' dotplots to assess the presence of 185 outliers within the dataset. We investigated multi-collinearity among explanatory variables 186 by means of scatterplots, Pearson correlation tests $(r)$, by setting the threshold for 187 collinearity at $r|0.7|$ (Zuur, leno, Walker, Savaliev, \& Smith, 2009). Boxplots were also 188 constructed to graphically assess collinearity between continuous and categorical 189 variables.

To model the response of the web coverage to the explanatory variables, we initially

191 fitted a Poisson generalised linear model (GLM), including all non-collinear covariates of 192 interest. In order to test for the potential effect of the different light source illuminating the 193 plot, we allowed for interactions between the artificial light intensity and the distance from 194 the different light sources (Dst_lamp * ILL; Dst_halo * ILL). The Poisson GLM was highly 195 over-dispersed [dispersion statistic $(D S)=600.95$ ], and thus a negative binomial GLM was 196 considered (Zuur et al., 2010). We fitted the negative binomial GLM in the MASS R 197 package (Venables \& Ripley, 2002). Over-dispersion in the negative binomial GLM was 198 minimal ( $D S=1.62)$, so we chose this error distribution in all subsequent analysis.

199 Once we fitted the initial negative binomial GLM including all the covariates and 200 interactions of interest, we performed model selection in order to select which variables 201 should be included in the final model (Johnson \& Omland, 2004). We used a stepwise 202 backward elimination procedure, whereby we progressively excluded variables and 203 interactions from the model according to the corrected Akaike information criterion for finite 204 sample size (AICc values; Burnham \& Anderson, 2002; Hurvich \& Tsai, 1989). We 205 reiterated the procedure until we obtained a Minimum Adequate Model (MAM) including 
only significant variables. We conducted model selection using the MuMIn $\mathrm{R}$ package

207 (Bartoń, 2017).

208 Model validation was conducted on the MAM (Zuur et al., 2009). In particular, we

209 tested it for over-dispersion, we constructed standard validation plots using model

210 residuals and we investigated the existence of possible non-linear responses of our

211 covariates by means of generalized additive models (GAMs). GAMs were fitted with the

212 gam R package (Hastie, 2013), using the same model structure identified during model

213 selection.

$215 \quad 2.5$ GIS analysis

216 For each sampling plot, we predicted the value of web coverage using the most

217 appropriate model structure supported by the observations derived from the model

218 selection. In order to provide a graphical representation of the investigated phenomenon in

219 the study area, we interpolated these predicted values in a GIS environment using the

220 methodology detailed in Mammola and Isaia (2016). For this analysis, we drew the vector

221 layer of the arcades on the raster topographical map of the study area, and we

222 interpolated the projected values for each sampling plot relative to each sampling session.

223 For the interpolation, we used an Inverse Distance Weighted function (IDW) using a

224 sample of 12 plots (power 2) to estimate cell values and obtain the renderings of the model

225 prediction. 
228 Following the initial data exploration (Zuur et al., 2010), we dropped R, B and G light 229 components from the GLM analysis, being collinear with artificial light intensity (all Pearson $230 \quad>0.9$ ). Moreover, we dropped the distance from the river (Dst), being collinear with the 231 inter-plot crossed distance (InterDst) and we excluded substrate temperature $\left(\mathrm{T}^{\circ}\right)$ from the 232 analysis, being collinear with the sampling session. We further applied a log233 transformation to artificial light intensity to achieve homogenization of its distribution (Zuur 234 et al., 2009), and removed one outlier from the dataset. According to model selection (Table 1), the MAM had the following structure: WEB $\log (\mathrm{ILL}) \times$ Dst_lamp + Sampling. Specifically, we found a positive and significant

238 lamppost, whereby higher web coverage was predicted at higher values of light intensity 239 and in the vicinity of historical lamppost. The effect of this interaction can be visualized in

240 Figure 4. We also detected a pattern of seasonal variation in the density of webs on the 241 arcades, with significantly higher predicted values in summer with respect to spring 242 (reference category). Coverage in winter was not significantly different from the reference 243 category (Figure 4). Estimated regression parameters and $p$ values are reported in Table 2442 , and a graphical representation of the model prediction is shown in Figure 3.

There was a significant spatial association in the web coverage among plots 246 (Moran's I test, observed $=-0.022$; expected $=-0.006 ; s d=0.005 p<0.05$ ). However, this 247 effect was not recovered in the regression analysis, given that the variable InterDST was 248 not significant and thus dropped from the model during the backward elimination model 249 selection procedure. Spatial association of webs can be visualized graphically in Figure 3 250 (note the conditional size of the dots representing the plots). 
253 The two strongest predictors of the web coverage of Brigittea civica in the historical

254 arcades of Turin were the intensity of artificial light and the distance from the nearest

255 historical (incandescent) lamppost. Moreover, we found a variation in the web coverage

256 with respect to the sampling session (Figure 3). It is well demonstrated that artificial

257 illuminance plays an important ecological role in urban settings (e.g., Gaston \& Bennie,

258 2014; Gaston, Bennie, Davies, \& Hopkins 2013; Sanders \& Gaston, 2018) and other

259 studies have reported about the significant association between different urban species

260 and artificial lighting (e.g. Frank, 2009; Heiling, 1999; but see Voss, Main, \& Dadour,

261 2007). As far as Brigittea civica is concerned, Samu et al. (2004) reported that (p. 355):

262 "[...] casual observation [...] showed that [B. civica] webs were aggregated around artificial

263 lights." Our work provides statistical support to this observation, as we demonstrated that

264 the web coverage of the plots was significantly higher in the plots where artificial light was

265 more intense.

It was observed that spiders thriving in urban habitats may benefit from increased

267 trophic resources in cities (Lowe, Wilder, \& Hochuli, 2016; Trubl, Gburek, Miles, \& 268 Johnson, 2012; Voss et al., 2007). Based upon this premise, the relationship between web 269 coverage and artificial light that we observed, could be explained as a function of the 270 higher prey availability found in the nearby of light sources (Heiling, 1999). The attraction

271 of aerial and terrestrial arthropods to artificial lighting is indeed a well-documented

272 phenomenon (Davies, Bennie, \& Gaston, 2012; Eisenbeis, 2006; Frank, 2006; Shimoda \&

273 Honda, 2013). It has been shown that $B$. civica is able to feed upon a wide range of small

274 flying insects - including dipterans, but also flying ants, small lepidopterans and aphids.

275 Also, if previously starved of food, these spiders are able to feed upon prey nearly three 
276 times bigger than themselves (Billaudelle, 1957). This wide range of potential prey is

277 expected to be available in the areas surrounding street lights (Davies et al., 2012).

278 Our data also demonstrate that the type of light source is important in explaining the 279 coverage of webs. In particular, spider webs were more abundant in the vicinity of

280 incandescent historical lampposts (Figure 3) rather than halogen lamps. We assume that 281 the light emitted by lampposts has its greater effects on attracting spiders due to its higher 282 potential of attracting insect prey. It is well-documented that nocturnal insects are able to 283 see ultraviolet radiation, being often attracted to light sources that emit large amounts of 284 UV radiation (Shimoda \& Honda, 2013). At the same time, different light spectra have 285 different attraction potential to nocturnal arthropods (e.g. Longcore et al., 2015), with 286 incandescent lights often attracting most nocturnal insects (Justice \& Justice, 2016). This 287 would convincingly explain the interaction we observed between light intensity and the 288 distance from the incandescent light sources.

289 One could argue that the incandescent artificial lighting system may affect the 290 distribution of the spiders because of the general influence on thermal conditions, rather 291 than because of its light spectrum. In fact, there should be higher ambient temperature in 292 the vicinity of lights, offering a more favourable habitat for a southern European species 293 such as $B$. civica. However, we rejected this alternative explanation given that the 294 temperature of the substrate was only limitedly anti-correlated with the distance from the 295 incandescent artificial lighting system $(r=-0.26)$.

There is evidence indicating that spiders may be able to recognise the quality of

297 foraging patches and change web site on the basis of prey availability (e.g., Enders, 1977;

298 Gillespie \& Caraco, 1987; Harwood, Sunderland, \& Symondson, 2001; but see Vollrath, 299 1985). Conversely, it may also be that habitat patches with higher light intensity, and thus 300 higher prey availability, are not actively selected by the spiders, but simply support larger 301 colonies of spiders, due to their more favourable condition. It stands to reason that the 
302 individual fitness of a spider should be higher in a prey-rich rather than in prey-poor habitat

303 patch. However, further studies are needed to determine whether the optimal patches are

304 actively selected by the spiders, or if the higher web coverage found in the vicinity of 305 incandescent lampposts is the actual results of a higher persistence of the local 306 population.

307 It is likely that the effect of artificial lighting was particularly clear-cut in our case

308 because, through the design of the study, we were able to exclude other confounding

309 factors. It has been shown that $B$. civica avoids areas exposed to rains, winds and direct

310 solar irradiation (Billaudelle, 1957; Samu et al., 2004). By using our study design (all plot in

311 sheltered arcades), we were able to exclude these factors from the analysis. Moreover, we

312 deliberately avoided plots with significant cracks and crevices in the plaster, which are

313 preferentially selected as supporting framework for the construction of webs and may thus

314 influence the fine distribution of this species.

\subsection{Management implications}

317 It has been argued that there is not an easy solution to the contamination of urban wall

318 surfaces by spider webs of Brigittea civica, mainly because this species does not show a

319 selective preference for a particular wall material or painting (Samu et al., 2004). As far as

320 we are aware, the only method so far implemented to deal with this issue is the

321 mechanical removal of the spider webs from the wall surfaces. Whilst the mechanical

322 removal is certainly effective, such methodology is rather costly, time consuming and

323 problematic, especially in the case of high buildings. Secondly, the mechanical removal

324 only represents a temporary remedy to the problem, needing to be reiterated over time.

325 There are three general findings relevant to the management of building surfaces

326 arising from this work. First, the timing of the mechanical cleaning can be important. Whilst

327 this may seem self-evident, we suggest that it is important to consider carefully the 
328 phenology of the species when planning the cleaning activities. We documented a higher

329 prevalence of webs during the warm seasons (Figure 4). In particular, a higher web 330 coverage was observed in summer, at the end of the breeding season of $B$. civica 331 (Kostanjšek \& Celestina, 2008; Nentwig et al., 2018; Wiehle, 1953). This observation 332 suggests that, in order to maximise the effect of the mechanical removal of the webs, one 333 should perform the cleaning after the summer peak of density.

334 Second, we showed that the incandescent artificial lighting systems illuminating 335 most of the arcades in our study area is the main trigger of the increase of the web 336 coverage (Figure 4). Thus, a renovation of the artificial lighting illuminating in the down337 town districts of heritage cities towards halogen or light emitting diode (LED) lights may 338 provide a near-permanent solution to this problem, or it may at least contribute to mitigate 339 the contamination. According to our results, arcades and building facades should become 340 a less attractive habitats for spiders, thereby reducing the aesthetic nuisance caused by 341 the webs.

342 Third, casual observations during this study revealed that cracks and crevices in the 343 plaster are preferentially used as supporting framework for the construction of webs. 344 Maintaining an intact plaster, at least in the touristic areas, will likely help in reducing the 345 intensity of the phenomenon.

$346 \quad$ Ultimately, it can be argued that heavy traffic exacerbates the phenomenon, given 347 that webs became more visible due to air pollution - see argumentation in Samu et al. 348 (2004). Pedestrian areas have been introduced in most of the historical down-town 349 districts of cities all around the world, with the aim of increasing commercial and touristic 350 activities, meanwhile reducing pollution to preserve historical sites (Pagliaria \& Biggiero, 351 2013). Accordingly, an increase of pedestrian areas associated to a reduction of the local 352 air pollution in down-town districts will, in turn, limit the aesthetic impact associated with $B$. 353 civica webs. 


\section{$355 \quad 4.2$ Significance statement}

356 One may argue that the results of this study might not be applied to spiders more widely

357 and that Brigittea civica might represent only a very specific case. Still, it is worth noting

358 that, despite being of southern European origin, this species has been spreading

359 northward during the last few years. Currently, B. civica reaches central Siberia and central

360 Asia (Buchar \& Růžička, 2002; Zamani \& Mozaffarian, 2017). Recent evidence indicate

361 that the species is much more common than was previously known; for instance, in

362 Central Europe it is likely that its presence has been underestimated (data from Czech

363 Republic; Novotný et al., 2017; see also discussions in Hänggi \& Straub, 2016). Moreover,

364 the spider was recently found in North America (World Spider Catalog, 2018) and South

365 Africa (Foord, 2014), which poses additional concerns in light of the potential economic

366 importance of the potential aesthetic damage caused by this species.

Moreover, this study exemplifies a methodological approach that is efficient and

368 inexpensive, and thus that can be easily reproduced in other cases. More studies similar to

369 this one would be useful when considering other species which are known to have

370 potentially negative aesthetic impacts, or that may even cause potential structural

371 damages. For instance, the photography-based methodology herein described can be

372 easily used to estimate the density of other organisms which may occur at high densities

373 - even forming biofilms - on wall surfaces, especially lichens, mosses, and fungi (e.g. de

374 los Ríos et al., 2009 Gaylarde \& Morton, 1999; Lisci, Monte, \& Pacini, 2003). 
383 Akamatsu, F., Toda, H., \& Okino, T. (2004). Food source of riparian spiders analyzed by 384 using stable isotope ratios. Ecological Research, 19(6), 655-662. doi - 10.1111/j.1440-

$385 \quad 1703.2004 .00680$

386

Aronson, M. F. J., La Sorte, F. A., Nilon, C. H., Katti, M., Goddard, M. A., Lepczyk, C. A.,

Warren, P. S., Williams, N. S. G., Cilliers, S., Clarkson, B., Dobbs, C., Dolan, R., Hedblom,

M., Klotz, S., Kooijmans, J. K., Kühn, I., MacGregor-Fors, I., McDonnell, M., Mörtberg, U.,

Pyšek, P., Siebert, S., Sushinsky, J., Werner, P., \& Winter, M. (2014). A global analysis of the impacts of urbanization on bird and plant diversity reveals key anthropogenic drivers. Proceedings of the Royal Society B Biological Science, 281, 20133330. doi -

Bartoń, K. (2017). MuMIn: Multi-Model Inference. R package version 1.40.0.

https://CRAN.R-project.org/package=MuMIn

Bertone, M. A., Leong, M., Bayless. K. M., Malow, T. L. F., Dunn, R. R., \& Trautwein, M. D.

(2016). Arthropods of the great indoors: characterizing diversity inside urban and suburban

402 Billaudelle, H. (1957). Zur biologie der mauerspinne Dictyna civica (H. LUC.) (Dictynidae:

403 Araneida). Zeitschrift für Angewandte Entomologie, 41, 475-512.

405 Buchar, J., \& Kubcová, I. (2002). Pavoučí tvář Prahy (The Spidery Face of Prague). Živa, $406 \quad 50,217-218$. 
Burnham, K. P., \& Anderson, D. R. (2002). Model selection and multi model inference:

409 apractical information-theoretic approach. New York - Springer-Verlag.

410

411 Davies, T. W., Bennie, J., \& Gaston, K. J. (2012). Street lighting changes the composition

412 of invertebrate communities. Biology Letters, 8(5), 764-767. doi - 10.1098/rsbl.2012.0216

414 de los Ríos, A., Cámara, B., del Cura, M. Á. G., Rico, V. J., Galván, V., \& Ascaso, C. 415 (2009). Deteriorating effects of lichen and microbial colonization of carbonate building 416 rocks in the Romanesque churches of Segovia (Spain). Science of the Total Environment, 417 407(3), 1123-1134. doi - 10.1016/j.scitotenv.2008.09.042

419 Eisenbeis, G. (2006). Artificial night lighting and insects: attraction of insects to street 420 lamps in a rural setting in Germany. In Rich, C., \& Longcore, T. Ecological consequences 421 of artificial night lighting (pp. 281-304). Washington, DC - Island Press.

423 Elliott, C., Vijayakumar, V., Zink, W., \& Hansen, R. (2007). National instruments LabVIEW:

424 a programming environment for laboratory automation and measurement. JALA: Journal of 425 the Association for Laboratory Automation, 12(1), 17-24. doi - 10.1016/j.jala.2006.07.012

427 Enders, F. (1977). Web-site selection by orb-web spiders, particularly Argiope aurantia 428 Lucas. Animal Behaviour, 25, 694-712. doi - 10.1002/dev.420020212

430 Foord, S. (2014). Recent records for three exotic spider species in South Africa. Cape

431 Town Invasives News. Retrieved 17 November 2016 from

432 http://www.capetowninvasives.org.za/news/2014/05/recent- records- three- exotic433 spider- species- south- africa 
435 Frank, K. D. (2006). Effects of artificial night lighting on moths. In Rich, C., \& Longcore, T.

436 Ecological consequences of artificial night lighting (pp. 305-344). Washington, DC - Island 437 Press.

438

439 Frank, K. D. (2009). Exploitation of artificial light at night by a jumping spider. Peckhamia, 440 78(1), 1-3. doi - 10.1007/978-3-540-48348-9_1

442 Gaston, K. J., \& Bennie, J. (2014). Demographic effects of artificial nighttime lighting on 443 animal populations. Environmental Reviews, 22(4), 323-330. doi - 10.1139/er-2014-0005

445 Gaston, K. J., Bennie, J., Davies, T. W., \& Hopkins, J. (2013). The ecological impacts of 446 nighttime light pollution: a mechanistic appraisal. Biological Reviews, 88(4), 912-927. doi $44710.1111 /$ brv.12036

449 Gaylarde, C. C., \& Morton, L. G. (1999). Deteriogenic biofilms on buildings and their 450 control: a review. Biofouling, 14(1), 59-74. doi - 10.1080/08927019909378397

452 Gillespie, R. G. (1987). The mechanism of habitat selection in the long-jawed orb-weaving 453 spider Tetragnatha elongata (Araneae, Tetragnathidae). Journal of Arachnology, 15(1), 8145490.

456 Gillespie, R. G., \& Caraco, T. (1987). Risk-sensitive foraging strategies of two spider

457 populations. Ecology, 68, 887-899. doi - 10.2307/1938360 
459 Gittleman, J. L., \& Kot, M. (1990). Adaptation: statistics and a null model for estimating 460 phylogenetic effects. Systematics Zoology, 39, 227-241. doi - 10.2307/2992183

461

462 Grimm, N. B., Faeth, S. H., Golubiewski, N. E., Redman, C. L., Wu, J., Bai, X., \& Briggs, 463 J. M. (2008). Global change and the ecology of cities. Science, 319(5864), 756-760. doi $464 \quad 10.1126 /$ science.1150195

466 Güneralp, B., \& Seto, K. C. (2013). Futures of global urban expansion: uncertainties and 467 implications for biodiversity conservation. Environmental Research Letters, 8, 014025. doi $468-10.1088 / 1748-9326 / 8 / 1 / 014025$

470 Hänggi, A., \& Straub, S. (2016). Storage buildings and greenhouses as stepping stones for 471 non-native, potentially invasive spiders (Araneae)-a baseline study in Basel, Switzerland. 472 Arachnologische Mitteilungen, 51, 1-8. doi - 10.5431/aramit5101

474 Harwood, J. D., Sunderland, K. D., \& Symondson, W. O. C. (2001). Living where the food 475 is: web location by linyphiid spiders in relation to prey availability in winter wheat. Journal 476 of Applied Ecology, 38(1), 88-99. doi - 10.1046/j.1365-2664.2001.00572

478 Hastie, T. (2013). gam: Generalized Additive Models. R package version 1.09. http:// 479 CRAN.R-project.org/package=gam.

481 Havlová, V., \& Hula, V. (2010). The Dictyna civica, a cribellate web building spider, causes 482 dirty facades. Živa, 2010(4), 172-173. 
Heiling, A. M. (1999). Why do nocturnal orb-web spiders (Araneidae) search for light?

485

Behavioral Ecology and Sociobiology, 46(1), 43-49. doi - 10.1007/s002650050590

486

487 Hertel, R. (1968). Über das Auftreten der südeuropäischen Spinne Dictyna civica (H. Luc.)

488 in Dresden (Dictynidae, Araneida). Abhandlungen des Naturkundemuseums Görlitz, 44, $48989-94$.

490

491 Hurvich, C. M., \& Tsai, C. L. (1989). Regression and time series model selection in small

492 samples. Biometrika, 76, 297-307. doi - 10.1093/biomet/76.2.297

494 Isbister, G. K., Gray M. R., Balit C. R., Raven R. J., Stokes B. J., Porges K., Tankel A. S., 495 Turner E., White J., \& Fisher M. M. (2005). Funnel-web spider bite: a systematic review of 496 recorded clinical cases. The Medical Journal of Australia, 182(8), 407-411.

498 Johnson, J. B., \& Omland, K. S. (2004). Model selection in ecology and evolution. Trends 499 in Ecology and Evolution, 19(2), 101-108. doi - 10.1016/j.tree.2003.10.013.

501 Justice, M. J., \& Justice, T. C. (2016). Attraction of insects to incandescent, compact 502 fluorescent, halogen, and led lamps in a light trap: implications for light pollution and urban

503 ecologies. Entomological News, 125(5), 315-326. doi - 10.3157/021.125.0502 504

505 Kleinteich, A. (2010). Life history of the bridge spider, Larinioides sclopetarius (Clerck, 506 1757). PhD thesis, University of Hamburg, Hamburg, Germany. Retrieved from: https://d507 nb.info/999993666/34 
509 Kostanjšek, R., \& Celestina, A. (2008). New records on synanthropic spider species

510 (Arachnida: Araneae) in Slovenia. Natura Sloveniae, 10(1), 51-55.

511

512 Krumpálová, Z. (2001). The synantropic spider Dictyna civica (Lucas, 1850) (Araneae,

513 Dyctinidae) in Slovakia. Sborník přirodovědného klubu v Uherském Hradišti, 6, 82-85.

515 Lisci, M., Monte, M., \& Pacini, E. (2003). Lichens and higher plants on stone: a review.

516 International Biodeterioration \& Biodegradation, 51(1), 1-17. doi - 10.1016/S0964-

$5178305(02) 00071-9$

518

519 Longcore, T., Aldern, H. L., Eggers, J. F., Flores, S., Franco, L., Hirshfield-Yamanishi, E.,

520 Petrinec, L. N., Wilson, Y. A., \& Barroso, A. M. (2015). Tuning the white light spectrum of

521 light emitting diode lamps to reduce attraction of nocturnal arthropods. Philosophical

522 Transactions of the Royal Society B: Biological Sciences, 370(1667), 20140125. doi -

$523 \quad 10.1098 /$ rstb.2014.0125

525 Lowe, E. C., Wilder, S. M., \& Hochuli, D. F. (2016). Persistence and survival of the spider 526 Nephila plumipes. Urban Ecosystems, 19(2), 705-720. doi - 10.1007/s11252-015-0518-9

528 Mammola, S., \& Isaia, M. (2016). The ecological niche of a special- ized subterranean

529 spider. Invertebrate Biology, 135, 20-30. doi - 10.1111/ivb.12113

531 Mclntyre, N. E. (2000). Ecology of urban arthropods: a review and a call to action. Annals 532 of the Entomological Society of America, 93(4), 825-835. doi - 10.1603/0013$533 \quad 8746(2000) 093$ 
535 McKinney, M. L. (2002). Urbanization, biodiversity, and conservation. Bioscience, 52, 883-

536 890. doi - 10.1641/0006-3568(2002)052

537

538 McKinney, M. (2008). Effects of urbanization on species richness: a review of plants and

539 animals. Urban Ecosystems, 11, 161-76. doi - 10.1007/s11252-007-0045-4

541 Nedvěd, O., Pekár, S., Bezděčka, P., Líznarová, E., Řezáč, M., Schmitt, M., Sentenská, L. 542 (2011). Ecology of Arachnida alien to Europe. Biological Control, 56(4), 539-550. doi -

$543 \quad 10.1007 / \mathrm{s} 10526-011-9385-3$

544

545 Nentwig, W. (2015) Introduction, establishment rate, pathways and impact of spiders alien 546 to Europe. Biological Invasions, 17(9), 2757-2778. doi - 10.1007/s10530-015-0912-5

548 Nentwig, W., Blick, T., Gloor, D., Hänggi, A., \& Kropf, C. (2018). Spiders of Europe (Version

549 01.2018). Retrieved April 30, 2018 from www.araneae.unibe.ch. doi - 10.24436/1

551 Newbold, T., et al. (2015). Global effects of land use on local terrestrial biodiversity. Nature, $552520,45-50$. doi - 10.1038/nature14324

554 Novotný, B., Hula, V., \& Niedobová, J. (2017). Insufficiency in distributional faunistic data 555 in synanthropic spiders: a case study of the occurrence of Brigittea civica (Araneae, 556 Dictynidae) in South Moravia, Czech Republic. Acta Universitatis Agriculturae et 557 Silviculturae Mendelianae Brunensis, 65(3), 899-905. doi - 10.11118/actaun201765030899 558

559 Pagliara, F., \& Biggiero, L. (2013). Limited traffic zones and local economy development: 560 what's the Impact?. International Journal of Scientific Research, 2(12), 129-131. 
562 Paradis, E., Claude, J., \& Strimmer, K. (2004). APE: analyses of phylogenetics and 563 evolution in R language. Bioinformatics, 20, 289-290.

564

565 R Core Team (2017). R: A language and environment for statistical computing. R

566 Foundation for Statistical Computing, Vienna, Austria. http://www.R-project.org/.

569 Sams, H. H., Hearth, S. B., Long, L. L., Wilson, D. C., Sanders, D. H., \& King, L. E. (2001).

570 Nineteen documented cases of Loxosceles reclusa envenomation. Journal of the

571 American Academy of Dermatology, 44(4), 603-608. doi - 10.1067/mjd.2001.112380

573 Samu, F., Jozsa, Z., \& Csànyi, E. (2004). Spider web contamination of house facades:

574 habitat selection of spiders on urban wall surfaces. In Samu, F., \& Szinetàr, C. European

575 Arachnology 2002 (pp. 351-356). Budapest - Plant Protection Institute and Berzsenyi

576 College.

578 Sanders, D., \& Gaston, K. J. (2018). How ecological communities respond to artificial light

579 at night. Journal of Experimental Zoology Part A: Ecological and Integrative Physiology.

580 doi - 10.1002/jez.2157

581

582 Shochat, E., Stefanov, W. L., Whitehouse, M. E. A., \& Faeth, S. H. (2004). Urbanization 583 and spider diversity: influences of human modification of habitat structure and productivity.

584 Ecological Applications, 14(1), 268-280. doi - 10.1890/02-5341 
Shimoda, M., \& Honda, K. I. (2013). Insect reactions to light and its applications to pest

587

management. Applied Entomology and Zoology, 48(4), 413-421. doi - 10.1007/s13355-

$588 \quad 013-0219$

589

590 Seto, K. C., Gueneralp, B., \& Hutyra, L. R. (2012). Global forecasts of urban expansion to

5912030 and direct impacts on biodiversity and carbon pools. Proceedings of the National

592 Academy of Sciences of the United States of America, 109(40), 16083-16088. doi -

593 10.1073/pnas.1211658109

594

595 Taucare-Ríos, A., Brescovit, A., \& Canals, M. (2013). Synanthropic spiders (Arachnida:

596 Araneae) from Chile. Revista Ibérica de Aracnología, 23, 49-53.

597 doi - 10.13140/RG.2.1.3082.7124

598

599 Trubl, P., Gburek, T., Miles, L., \& Johnson, J. (2012). Black widow spiders in an urban

600 desert: population variation in an arthropod pest across metropolitan Phoenix, AZ. Urban

601 Ecosystems, 15(3), 599-609. doi - 10.1007/s11252-011-0223-2

602

603 Turnbull, A. L. (1973). Ecology of the true spiders (Araneomorphae). Annual Review of

604 Entomology, 18(1), 305-348. doi - 10.1146/annurev.en.18.010173.001513

605

606

Venables, W. N., \& Ripley, B. D. (2002). Modern Applied Statistics with S. Fourth Edition.

607 Springer - New York.

608

609 Vetter, R. S., \& Isbister, G. K. (2008). Medical aspects of spider bites. Annual Review of

610 Entomology, 53, 409-429. doi - 10.1146/annurev.ento.53.103106.093503

611 
612 Vitousek, P. M. (1997) Human domination of Earth's ecosystems. Science, 277, 494-499.

613 doi - 10.1126/science.277.5325.494

614

615 Vollrath, F. (1985). Web spider's dilemma: a risky move or site dependent growth.

616 Oecologia, 68(1): 69-72. doi - 10.1007/BF00379476

617

618 Voss, S. C., Main, B. Y., \& Dadour, I. R. (2007). Habitat preferences of the urban wall

619 spider Oecobius navus (Araneae, Oecobiidae). Austral Entomology, 46(4), 261-268. doi -

$620 \quad 10.1111 / \mathrm{j} .1440-6055.2007 .00616$

621

622 Wiehle, H. (1953) Spinnentiere oder Arachnoidea (Araneae), IX. Orthognatha-Cribellata-

623 Haplogynae, Entelegynae (Pholcidae, Zodariidae, Oxyopidae, Mimetidae, Nesticidae). Die 624 Tierwelt Deutschlands, 42, 1-150.

625

626 World Spider Catalog (2018). World Spider Catalog. Natural History Museum Bern.

627 Retrieved April 30, 2018 from http://wsc.nmbe.ch (version 18.5). doi - 10.24436/2 628

629 Zamani, A., \& Mozaffarian, F. (2017). Further spider (Arachnida: Araneae) material

630 deposited in the Agricultural Zoology Museum of Iran (AZMI), Iranian Research Institute of

631 Plant Protection. Arachnologische Mitteilungen, 54, 8-20. doi - 10.5431/aramit5403

632

633 Zuur, A. F., \& leno, E. N. (2016). A protocol for conducting and presenting results of 634 regression type analyses. Methods in Ecology and Evolution, 7, 636-645. doi -

$63510.1111 / 2041-210 X .12577$

636 
637 Zuur, A. F., leno, E. N., \& Elphick, S. C. (2010). A protocol for data exploration to avoid 638 common statistical problem. Methods in Ecology and Evolution, 1, 3-14. doi -

$63910.1111 / \mathrm{j} .2041-210 X .2009 .00001$

640

641 Zuur, A. F., leno, E. N., Walker, N. J., Savaliev, A. A., Smith, G. M. (2009) Mixed effect

642 models and extensions in ecology with R. Berlin - Springer.

643

644

645

646

647 
649 Table 1. Model selection according to the corrected Akaike criterion for finite sample size (AICc; Burnham \& 650 Anderson, 2002; Hurvich \& Tsai, 1989). Models are ordered from the most to the least appropriate.

\begin{tabular}{|c|c|c|c|c|}
\hline Model & df & AlCc & $\triangle \mathrm{AlCc}$ & wi \\
\hline $\begin{array}{l}\text { y log }(I L L)^{\star} \text { Dst_halo }+\log (I L L)^{\star} \text { Dst_lamp }+ \text { Sampling }+ \\
\text { InterDst }\end{array}$ & 10 & 2362.37 & 3.41 & 0.08 \\
\hline y log(ILL) ${ }^{\star}$ Dst_halo +Dst_lamp + Sampling + InterDst & 9 & 2360.35 & 1.40 & 0.21 \\
\hline y log(ILL)*Dst_halo + Dst_lamp + Sampling & 8 & 2359.72 & 0.77 & 0.28 \\
\hline y log(ILL)*Dst_halo + Sampling & 7 & 2358.95 & 0.00 & 0.42 \\
\hline
\end{tabular}

$653 \mathrm{Df}=$ degrees of freedom; $\mathrm{AICc}=$ Corrected Akaike information criterion for finite sample size; $\triangle \mathrm{AICc}=(\mathrm{AICc}$ 654 of themodel)—(AICc of the best model); wi = Akaike weight (sensu Burnham \& Anderson, 2002). See text for 655 abbreviationsof the explanatory variables.

658 Table 2. Estimated regression parameters and p-values according to GLM analysis. See text for 659 abbreviations of the explanatory variables.

\begin{tabular}{|l|c|c|c|c|}
\hline Variable & Estimated $\boldsymbol{\beta}$ & Standard Error & z-value & p-value \\
\hline Intercept & -7.3130 & 2.675 & - & - \\
\hline $\log (\mathrm{ILL})$ & 1.3224 & 0.254 & 5.201 & $<0.001$ \\
\hline Dst_lamp & 1.3912 & 0.548 & 2.537 & 0.011 \\
\hline log(ILL) x Dst_lamp & -0.1528 & 0.052 & -2.291 & 0.003 \\
\hline Sampling (level: December) & -0.1816 & 0.137 & -1.324 & 0.185 \\
\hline Sampling (level: July) & 1.3761 & 0.138 & 9.979 & $<0.001$ \\
\hline
\end{tabular}

660 


\section{FIGURE CAPTIONS}

668

669 Figure 1. A) Brigittea civica (Lucas) (Araneae: Dictynidae) (photo credits:

670 Dr. Hans-Juergen Thorns). B) Sampling plot on an arcade ceiling with a reduced density of cobwebs of $B$. 671 civica. C) Sampling plot on an arcade ceiling with a significant contamination of cobwebs of B. civica. D)

672 Sampling plot on an arcade ceiling entirely covered by cobwebs of $B$. civica. E) The historical arcades of 673 Turin in the area close to Palazzo Carignano. Arrows point at area covered by webs of B. civica (Photo 674 credits: Nicola Paccagnella - www.nicola.photos).

Figure 2. Schematic summary of the monitoring protocol.

678 Figure 3. Maps of the studied arcades showing interpolated surfaces of the predicted coverage of webs in 679 winter (a), spring (b) and summer (c) according to GLM results. Size of each sampling plot is proportional to 680 the observed web coverage.

682 Figure 4. Predicted relationship between the coverage of webs of Brigittea civica and the intensity of artificial 683 light (log-transformed) in interaction with the distance from the incandescent historical lamppost across the 684 three sampling sessions. To generate the predictions, two arbitrary values of distance from the incandescent 685 lamppost were used, namely zero (filled line) and six (dashed line) meters. Shaded grey surfaces are 95\% 686 confidence intervals. 

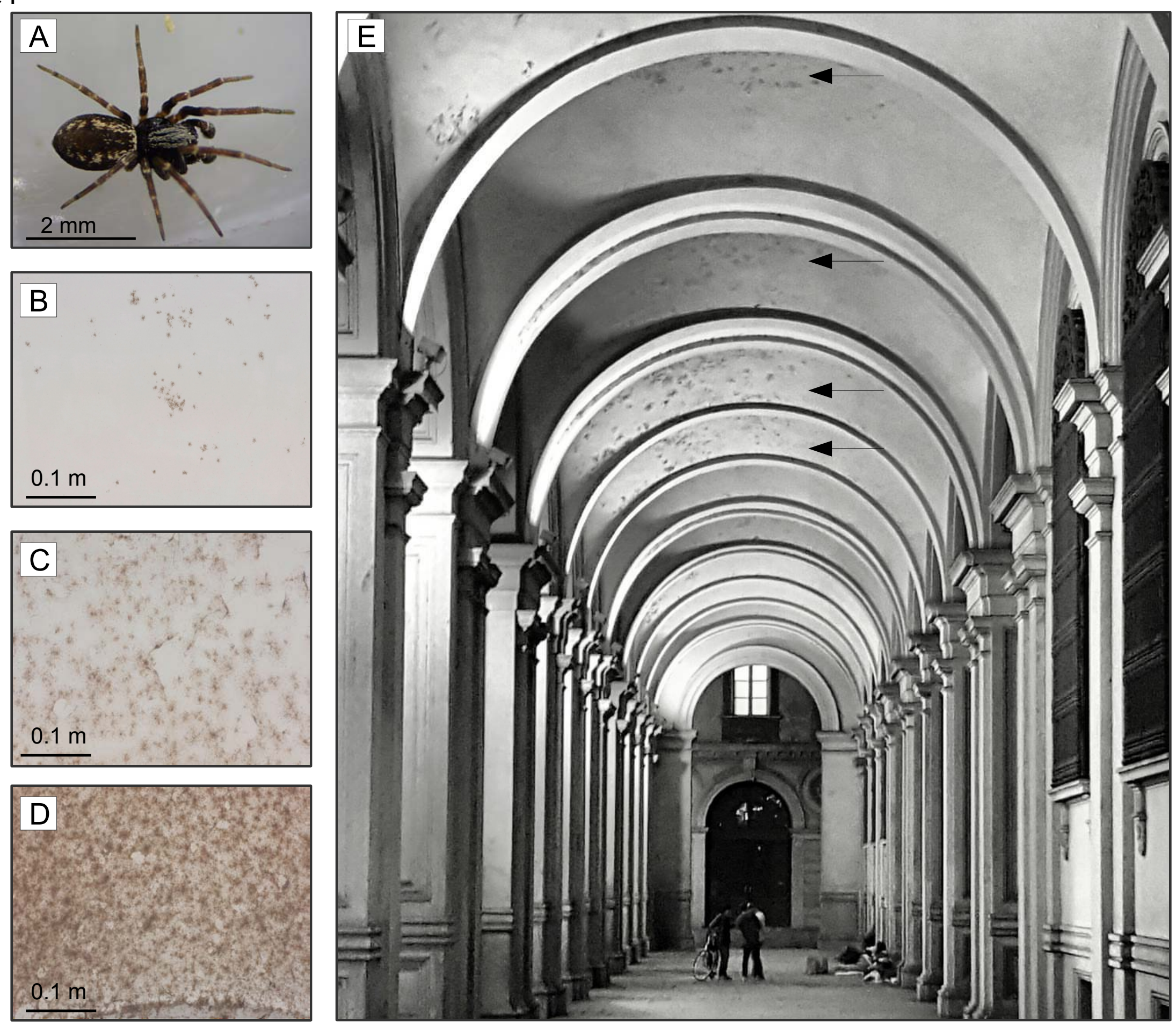


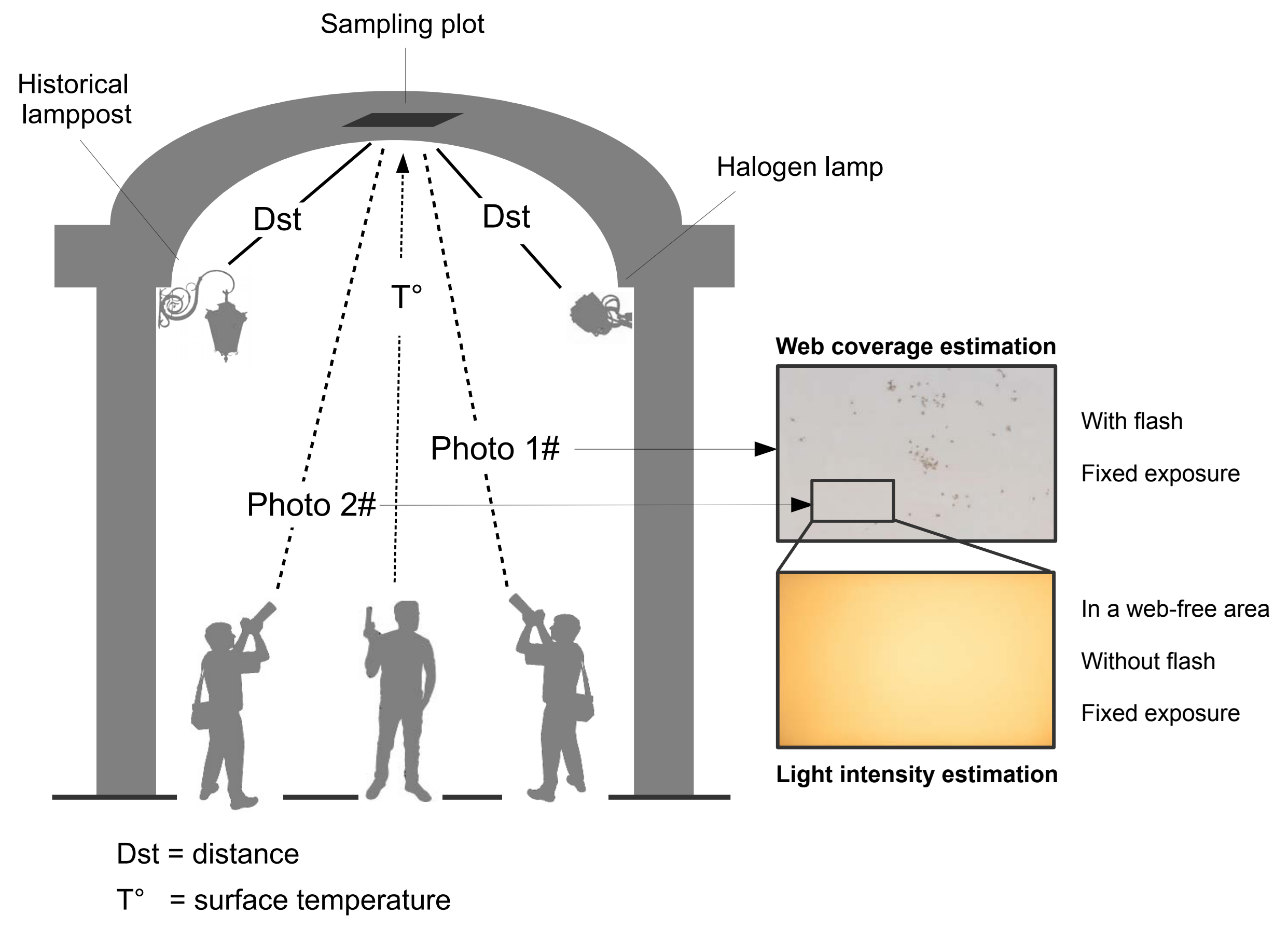




\section{Figure 3}

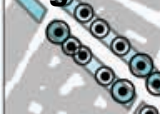

a. Winter
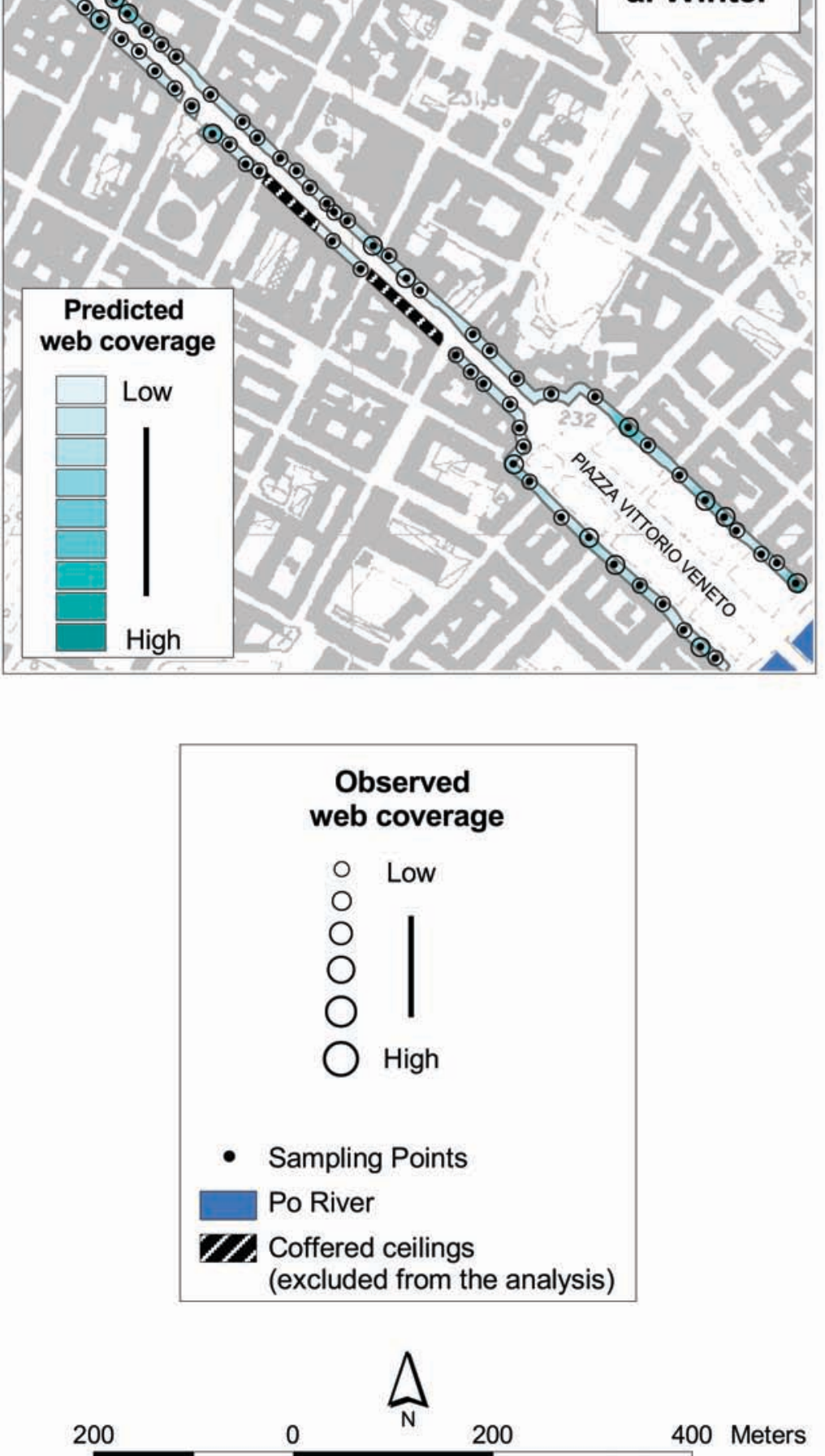
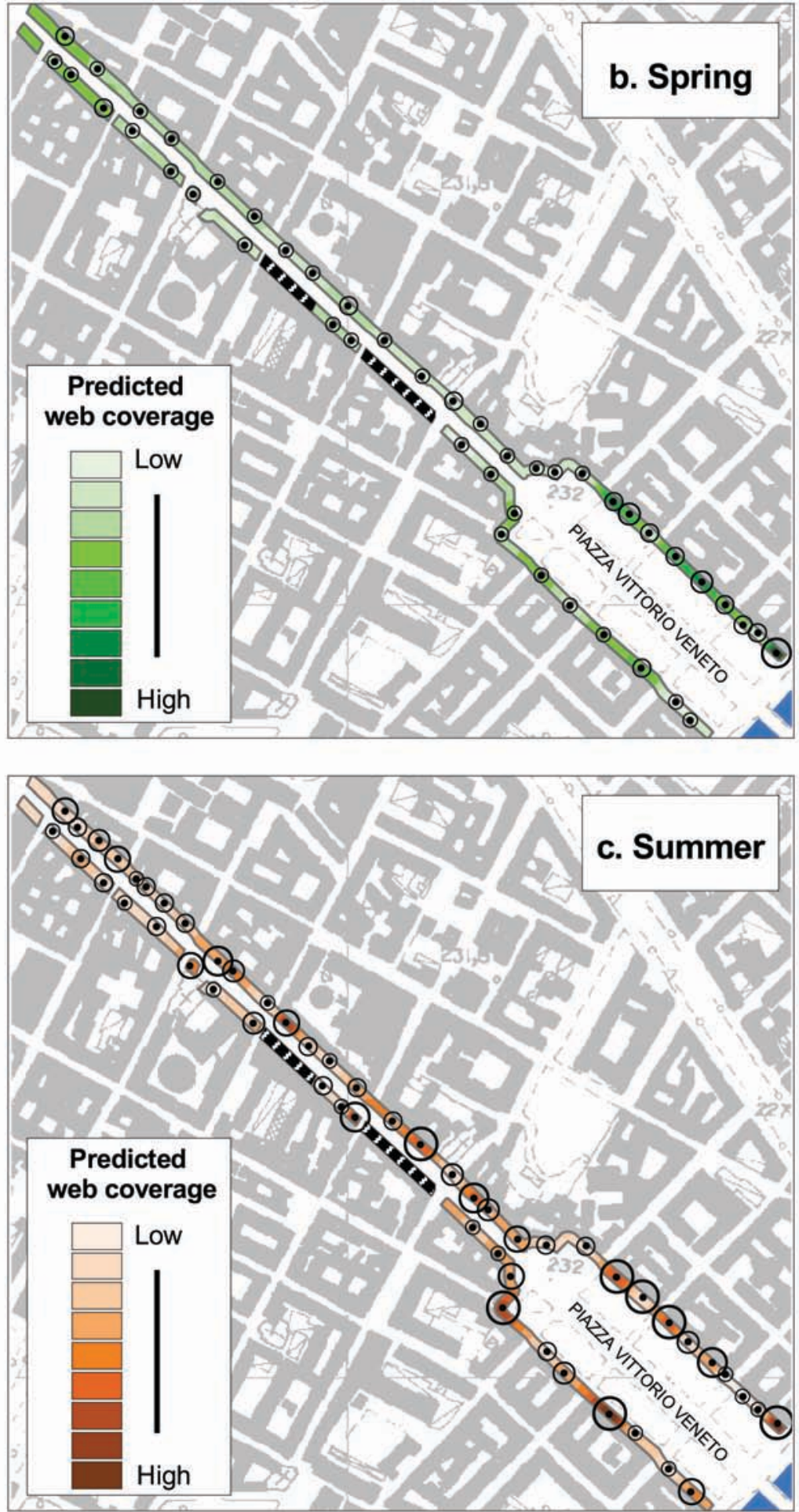
Figure 4

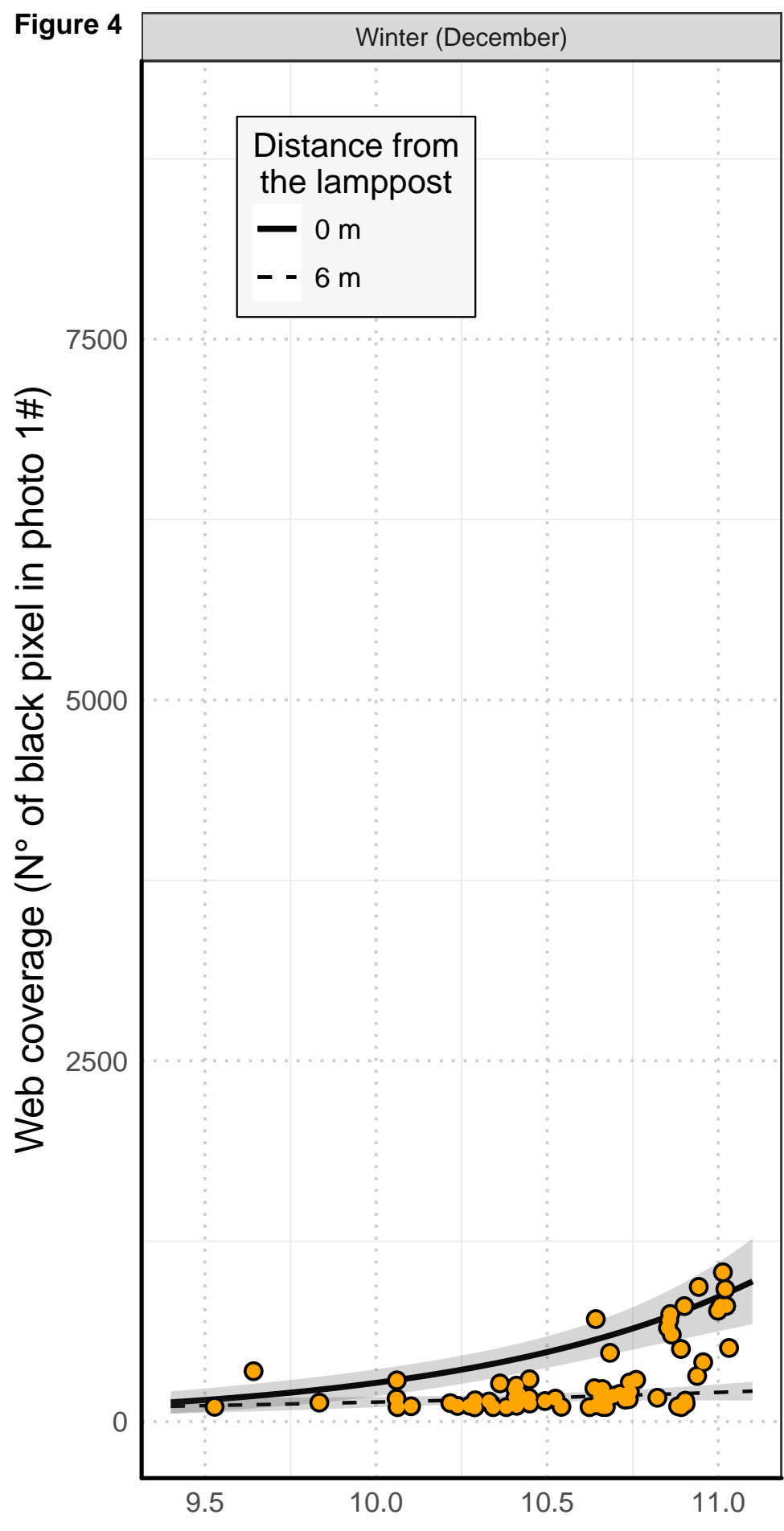

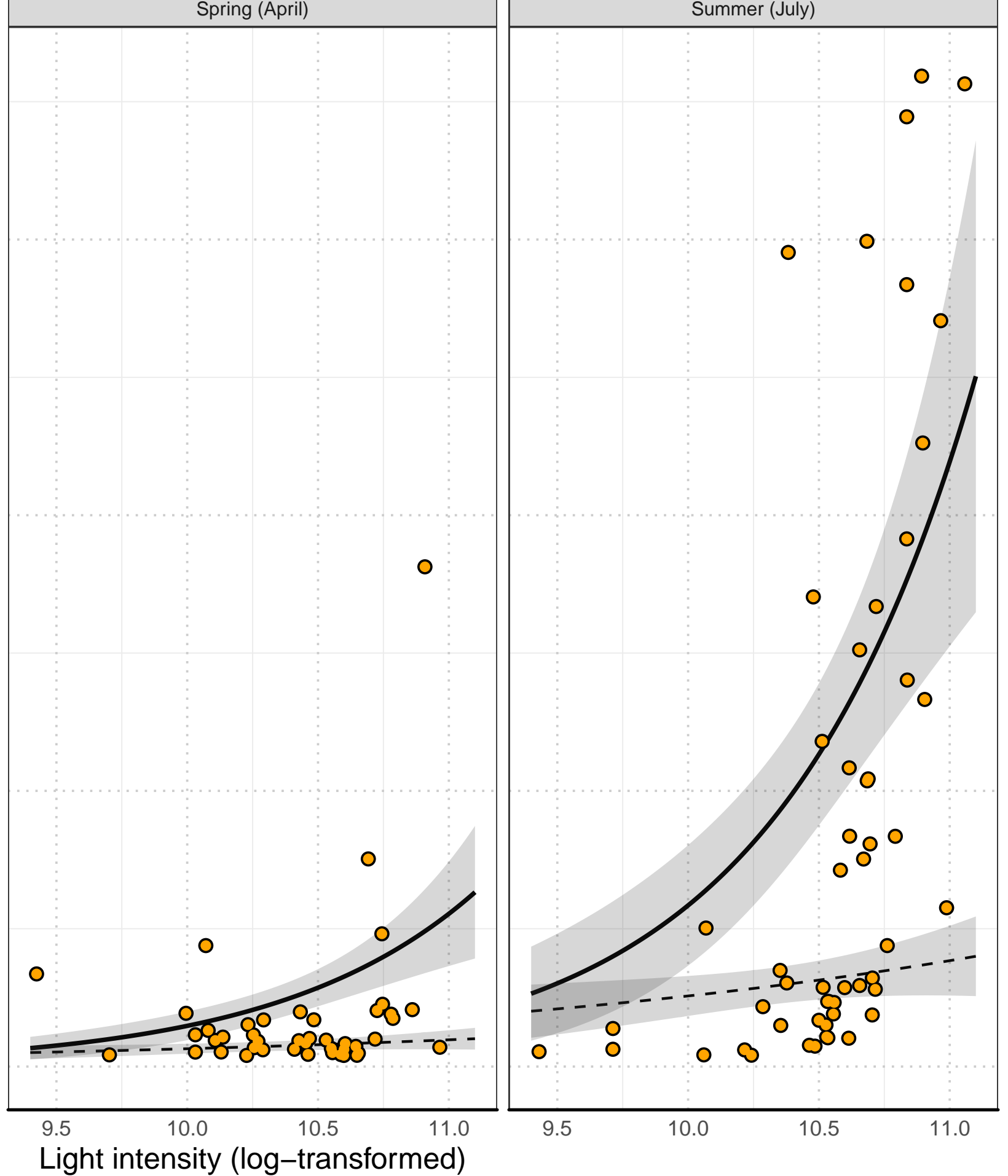



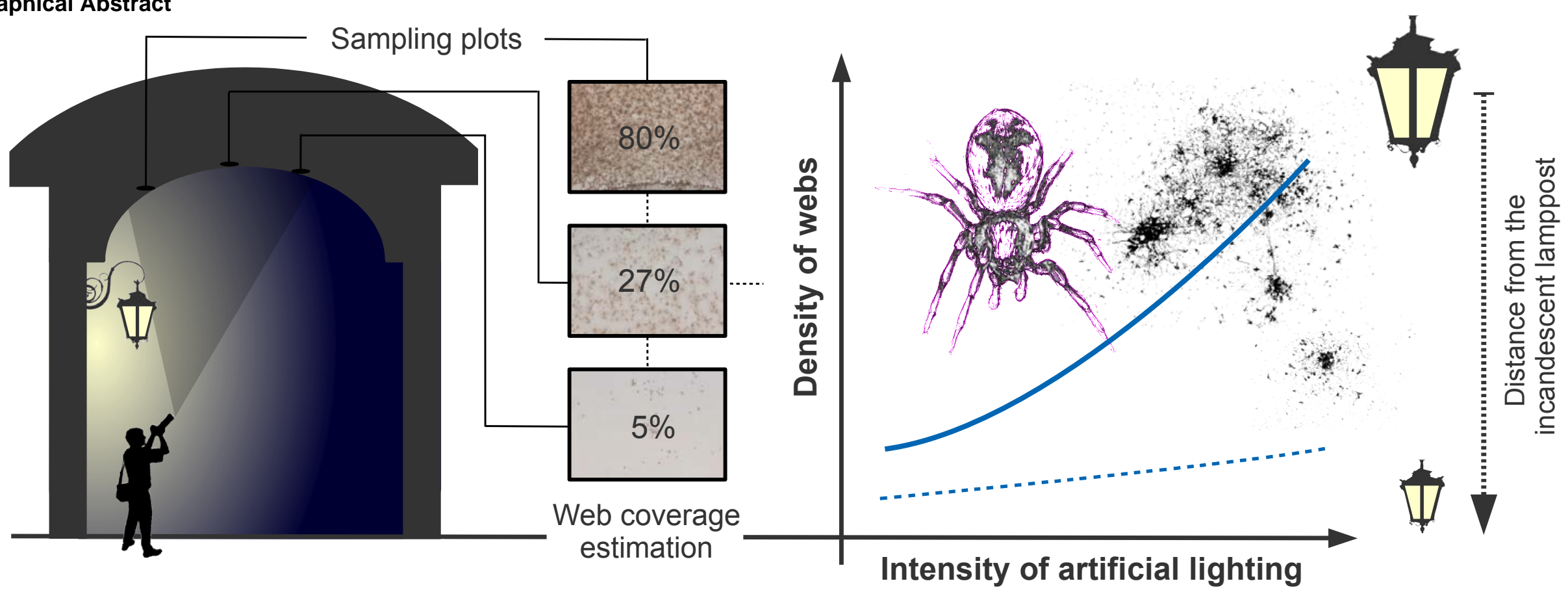

estimation
es coverage 


\section{ACKNOWLEDGMENTS}

2

3 This study is part of a wider research project on urban decay funded by Compagnia di San

4 Paolo. Special thanks go to Dr. Sara L. Goodacre for proofreading our English, to

5 Francesca Cochis for fieldwork assistance and to Prof. Wolfgang Nentwig for pre-revising

6 the manuscript. We thank Dr. Hans-Juergen Thorns and Nicola Paccagnella for sharing

7 with us photographs of Brigittea civica and its habitat (Figure 1).

8 